\title{
CONTRIBUIÇÃO DA OUVIDORIA PARA A GESTÃO DO ESTADO DO CEARÁ
}

\author{
Rossana Maria Guerra Ludueña ${ }^{1}$ \\ Paulo César de Sousa Batista²
}

\begin{abstract}
Resumo
Este trabalho tem como objetivo avaliar o sistema de Ouvidoria do Ceará sob os aspectos de estrutura e eficácia, representado pela contribuição para a melhoria da gestão e políticas públicas. As Ouvidorias são importantes ferramentas à disposição dos cidadãos e do estado para facilitar a construção de uma administração que atenda com qualidade aos anseios da sociedade. Metodologicamente, a pesquisa é qualitativa e descritiva, tendo como estratégia a realização de um estudo de caso de caráter descritivo. Foram aplicadas pesquisa documental e entrevistas presenciais, baseadas em questionários aplicados a uma amostra de 32 respondentes. Os resultados indicaram um sistema estruturalmente preparado para permitir que o cidadão participe da administração do serviço público de Ouvidoria, mas com contribuição ainda incipiente para a melhoria da gestão. Essa limitação resulta das posturas divergentes dos gestores quanto ao uso das informações.
\end{abstract}

Palavras-Chaves: Ouvidoria. Gestão Pública. Informação.

1 Mestre em Planejamento e Políticas Públicas pela Universidade Estadual do Ceará (Uece). Analista de Gestão de Tecnologia da Informação da Empresa de Tecnologia da Informação do Ceará (Etice). (rossanaluduena@gmail.com) (85) 988882587.

$2 \mathrm{PhD}$ em Economia pela University of Illinois, Estados Unidos. Membro efetivo do Programa de Pós-Graduação em Administração da Uece. Membro efetivo do Programa de Pós-Graduação de Políticas Públicas da Uece. (batista. pcs@gmail.com) (85) 988998675. 


\begin{abstract}
The objective of this study is to evaluate the Ombudsman system of Ceará under aspects of its structure and its effectiveness, represented by the contribution to the improvement of state management and public policies. Ombudsmen are important tools available to citizens and the state to facilitate the construction of an administration that meets the needs of society with quality. Methodologically, the research is qualitative and descriptive, having as strategy the accomplishment of a case study of descriptive character. Documentary research and face to face interviews, based on questionnaires, were applied to a sample of 32 respondents. The results indicated a structurally prepared system to allow the citizen to participate in the administration of the public Ombudsman service, but with an incipient contribution to the improvement of management. This limitation results from the divergent positions of managers regarding the use of information.
\end{abstract}

Keywords: Ombudsman. Public Administration. Information. 


\section{INTRODUÇÃO}

Para a pesquisa, foram feitas consultas bibliográficas iniciais aos autores VIEIRA e LIMA (2011), VISMONA (2011) e NASSIF (2009), que afirmam a necessidade dos governantes de ouvir os reclames da sociedade, pois é para esse atendimento que eles foram dotados do poder de governar. Esse poder não é exclusivo do gestor público, visto que, num processo democrático, toda a sociedade é responsável pela Administração Pública. Segundo os autores, a Constituição de 1988 afirma que o cidadão passa a fazer parte do cenário político como personagem importante para a construção da sua realidade. Existe a necessidade da criação de instrumentos que modernizem o Estado, estimulando a participação da sociedade na fiscalização do uso de recursos públicos e no combate ao desperdício e à corrupção, garantindo transparência ao exercício do poder público. Essa prática, chamada de controle social, passa a ter destaque na atual Administração Pública.

A Ouvidoria apresenta-se como um desses instrumentos, com o propósito de apoiar os gestores públicos na missão de oferecer serviços que atendam às demandas da sociedade, em consonância com as políticas públicas, além de atuar como instrumento de controle social. Alguns autores realçam o papel da Ouvidoria como parceira do gestor dentro da organização.

No Decreto Estadual n 30.938, de 10 de julho de 2012 (CEARÁ, 2012a), foram definidas novas políticas para a Ouvidoria do governo do estado, voltadas para a participação da sociedade e o exercício do controle social, iniciando uma experiência cuja análise e avaliação será útil a outros entes públicos envolvidos na melhoria dos serviços de Ouvidoria.

Diante disso, os autores deste trabalho elegeram como objetivos da pesquisa descrever a estrutura e o funcionamento da Ouvidoria do Ceará e o uso das informações produzidas por ela como contribuição para a gestão pública do estado. Metodologicamente, a pesquisa tem natureza mista, qualitativa e quantitativa. Como estratégia, foi realizado um estudo de caso da experiência de concepção e implantação do Sistema de Ouvidoria, com recurso a técnicas de pesquisa documental e a realização de entrevistas presenciais e aplicação de questionários. A amostra da pesquisa compreende 32 respondentes, Ouvidores, técnicos e gestores das unidades setoriais e do órgão central dessa Ouvidoria. O tratamento e a interpretação das informações coletadas foram feitos recorrendo à análise de conteúdo, segundo BARDIN (1977, p. 117 apud VERGARA, 2005, p. 18).

O Sistema de Ouvidoria do Ceará é composto pelo órgão central, inserido na Controladoria e Ouvidoria-Geral do Estado (CGE), e pela rede de Ouvidoria do governo, formada pelos órgãos e entidades do Poder Executivo estadual.

Para o cumprimento dos objetivos, o artigo está estruturado nesta introdução, seguida do desenvolvimento e das considerações finais. Dentro do desenvolvimento, encontram-se a fundamentação teórica, os procedimentos metodológicos e o resultado da pesquisa.

\section{ORGANIZAÇÃO E PAPEL DA OUVIDORIA}

O controle social, segundo MORAES et al. (2010, p. 24), é um termo utilizado em políticas públicas como uma "forma de participação democrática nos processos de gestão das instituições/ 
organizações no Brasil". Afirma, ainda, que "o controle social se caracteriza pela participação da sociedade nas funções de planejamento, monitoramento, acompanhamento e avaliação de resultados das políticas públicas" (MORAES et al., 2010, p. 24). A Constituição de 1988 (BRASIL, 1988) já previa a participação da sociedade na gestão pública, assegurando o direito de reclamação relativo ao serviço público prestado.

Nesse contexto, surge a Ouvidoria que, segundo PINTO (2011, p. 35), "deve-se constituir também órgão de controle para propiciar uma gestão pública focada no desejo da população", aproximando o cidadão da Administração Pública e atuando como instrumento de controle social.

Na opinião de OLIVEIRA (2005, p. 45), a Ouvidoria brasileira, mesmo diante de diferenças culturais e regionais, é hoje um canal de diálogo com a população; uma porta aberta para a participação popular, uma vez que ouve as reivindicações e suas recomendações oferecem oportunidades de melhoria do serviço público. É por meio da Ouvidoria que o cidadão se manifesta, reclamando da má administração e dos abusos da função pública, propondo a prática de novas ações pelo governo. A partir disso, a Administração Pública pode identificar pontos críticos de sua atuação e corrigi-los, incentivando a prática da responsabilização. Nesse cenário, NASSIF (2009, p. 52) reforça que as Ouvidorias Públicas assumem funções de mediação e vigilância, assegurando o cumprimento das leis e dos direitos da sociedade, por persuasão e esclarecimento das autoridades administrativas.

A Ouvidoria-Geral da Controladoria-Geral da União comenta que "a qualidade dos serviços prestados pela administração se aperfeiçoa com a atuação da Ouvidoria, uma vez que ela auxilia na identificação de pontos a serem aprimorados e contribui, dessa forma, para a melhoria dos procedimentos e dos processos administrativos" (BRASIL, 2012a, p. 12).

Dessa forma, a Ouvidoria tem a responsabilidade de analisar as manifestações recebidas da sociedade, e esses dados servem de base para informar ao dirigente maior do órgão a existência de problemas e propor recomendações. A partir dessas recomendações, podem ser sugeridas meIhorias nos processos internos da instituição e até mudanças estruturais.

GOIS, LACERDA e SOUZA (2011, p. 187) reconhecem a Ouvidoria como um canal privilegiado de informação e comunicação direta com a população. As recomendações vindas dela em forma de dados e relatórios gerenciais auxiliam os administradores no planejamento de novas ações para aperfeiçoar os serviços existentes, influenciando novas decisões.

O Poder Executivo brasileiro está gradativamente incorporando a Ouvidoria como parte da administração e estimulando a participação do cidadão, inclusive no conhecimento da atividade administrativa. Aos poucos, segundo VISMONA (2011, p. 29), a Ouvidoria foi fazendo parte da estrutura organizacional de instituições na iniciativa privada (áreas financeira, de seguros e de serviços, como rodovias, energia elétrica, telefonia, portos e aeroportos) e na Administração Pública direta e indireta da União, dos estados e dos municípios, no Poder Judiciário, Legislativo e no Ministério Público.

A Ouvidoria, segundo PINTO (2011, p. 35), tem o propósito de "oferecer informações gerenciais e sugestões ao dirigente do órgão, visando o aprimoramento da prestação de serviço público", seu papel não é apenas servir de canal. O tratamento das manifestações recebidas é útil para informar o gestor do órgão no qual atua sobre incidências de problemas, instigando mudanças estruturais, além de informar a sociedade a respeito de mudanças decorrentes do resultado de sua atuação.

Mesmo diante das constatações do papel da Ouvidoria, SOUZA (2010, p. 14) acrescenta que 
a participação dos usuários na utilização desse setor tem sido muito pequena e sua finalidade pouco percebida.

Com relação à estrutura da Ouvidoria, VISMONA (2011, p. 29) afirma que uma Ouvidoria deve ser instalada de modo estratégico na instituição, com atribuições claras e bem definidas, apoiada pela alta administração, de forma a garantir sua independência para apresentar sugestões, e com autonomia para verificar as causas das manifestações apresentadas pelo cidadão. Reforça ainda o autor que "uma Ouvidoria bem estruturada, com o respaldo da alta administração, com independência para apresentar suas sugestões e autonomia em verificar as causas das reclamações apresentadas, é um ótimo suporte para auxiliar na melhoria da qualidade de serviços" (VISMONA, 2011, p. 36).

\section{PROCEDIMENTOS METODOLÓGICOS DA PESQUISA}

Quanto à natureza e à abordagem do trabalho, trata-se de uma pesquisa qualitativa e descritiva por se basear em opiniões colhidas. Segundo GIL (2002, p. 42), as "pesquisas descritivas têm como objetivo primordial a descrição das características de determinada população ou fenômeno ou, então, o estabelecimento de relações entre variáveis".

Os dados foram coletados inicialmente por meio de pesquisa documental e bibliográfica, realizada de março de 2016 a agosto do mesmo ano, consultando as dissertações disponíveis na internet e os conteúdos de sites institucionais das Ouvidorias setoriais do governo do Ceará.

Posteriormente, foi realizada a fase de pesquisa de campo, por meio de entrevistas feitas com 32 respondentes, em dezembro de 2016, com auxílio de questionários semiestruturados. Eles foram elaborados com base em categorias preestabelecidas a partir da análise bibliográfica e documental e em linha com a orientação da análise de conteúdo, conforme segue:

a) qualificação e perfil do Ouvidor;

b) divulgação e canais de atendimento;

c) estrutura e posição hierárquica da Ouvidoria na organização do governo e nos órgãos setoriais, relacionamento com a alta gestão e participação no planejamento da instituição;

d) processo de atendimento às manifestações de Ouvidoria; e

e) tratamento e destino da informação gerada a partir das manifestações.

O universo dessa pesquisa é formado pelos gestores, Ouvidores e técnicos da rede de Ouvidorias do estado, a qual abrange 66 órgãos/entidades setoriais do executivo cearense e o órgão central de Ouvidoria localizado na CGE. Desse total, foi selecionada uma amostra de 32 respondentes, sendo 22 do órgão central e 10 Ouvidores de órgãos do estado que concentravam $80 \%$ das manifestações da sociedade em todos os canais disponíveis. Os órgãos selecionados foram: Secretaria da Saúde do Estado (Sesa), Secretaria da Educação (Seduc), Secretaria da Fazenda do Estado (Sefaz), Companhia de Água e Esgoto do Ceará (Cagece), Secretaria de Segurança Pública e Defesa Social (SSPDS), Polícia Militar do Estado do Ceará (PMCE), Instituto de Saúde 
dos Servidores do Estado do Ceará (Issec), Secretaria de Planejamento e Gestão (Seplag), Departamento Estadual de Trânsito (Detran-CE) e Polícia Civil do Estado do Ceará (PCCE).

Dentre os respondentes do órgão central de Ouvidoria encontram-se: o titular da pasta, o secretário adjunto e o secretário executivo, os gestores da Célula de Ouvidoria e da Célula de Acesso à Informação, o titular da Coordenadoria de Fomento ao Controle Social (Cfocs) - na qual as células de Ouvidoria e de Acesso à Informação estão inseridas - e mais seis técnicas da Ouvidoria.

Os dados coletados na pesquisa são referentes ao período de janeiro de 2007 a dezembro de 2015, período em que ocorreu a implantação do novo modelo de gestão do executivo cearense, com a publicação da Lei Estadual n 13.875, de 7 de fevereiro de 2007 (CEARÁ, 2007), que, na época, vinculou a Ouvidoria-Geral à Secretaria de Controladoria do Estado (Secon).

A análise dos dados foi feita também com recursos à técnica de análise de conteúdo. VERGARA (2005, p. 19) afirma ser essa técnica utilizada para tratamento dos dados cujo objetivo é mostrar com profundidade tudo sobre determinado tema. A modalidade de análise escolhida foi a fechada, com pré-seleção das categorias.

\section{RESULTADOS E DISCUSSÃO}

Os resultados apresentados a seguir baseiam-se nas informações coletadas por meio de pesquisa documental e das entrevistas com os integrantes do Sistema de Ouvidoria do Estado do Ceará. Os resultados mostram o atual modelo de estrutura e funcionamento da Ouvidoria - compreendendo as categorias de análise detalhadas na metodologia deste trabalho - e as evidências de mudanças realizadas pelos órgãos setoriais em resposta às recomendações e denúncias recebidas.

\subsection{Estrutura e Funcionamento do Sistema de Ouvidoria do Estado}

Referindo-se à qualificação e perfil do Ouvidor, de acordo com o modelo do Decreto 30.938/2012 (CEARÁ, 2012a), o Ouvidor do órgão setorial deve ser efetivo, designado pelo dirigente do órgão/ entidade e responder diretamente ao gestor titular do órgão ou ao gestor de uma área de assessoria da instituição. O perfil exigido para a função de Ouvidor nos órgãos setoriais compreende a atuação com ética, o conhecimento sobre a estrutura e a política da instituição, a governança corporativa e a informática, além da habilidade de mediar conflitos e da articulação no trato com usuários do serviço público e integrantes dos outros órgãos da administração.

Quanto ao critério de escolha do Ouvidor, os respondentes da pesquisa indicaram que os dirigentes dos órgãos e entidades da rede de Ouvidoria são orientados a indicar o profissional que atenda ao perfil exigido no Decreto $30.938 / 2012$, sem que para isso seja necessária a validação pela CGE. Contudo, os Ouvidores designados têm sua atuação avaliada pela Célula de Ouvidoria da CGE, segundo declarou o gestor dessa unidade.

Quanto à qualificação, $80 \%$ dos respondentes afirmaram que os Ouvidores são preparados para o exercício de suas atividades nos órgãos setoriais e na unidade central de Ouvidoria. $\mathrm{Na}$ 
opinião do coordenador da Coordenadoria de Fomento ao Controle Social (Cfocs)/CGE, as Ouvidorias de grande e médio porte - considerando o quantitativo do quadro funcional de efetivos e terceirizados - dedicam-se mais às atividades da área. Já nas de pequeno porte, em que o Ouvidor não é exclusivo e acumula outras atividades, torna-se difícil o desempenho. A Cfocs/CGE realiza cursos preparatórios (para Ouvidores iniciantes) e avançados, cursos para elaboração de relatórios de Ouvidoria, palestras, reuniões técnicas e encontros de Ouvidores bimestrais intersetoriais. Ainda assim, é mantida pelo órgão central a sistemática de capacitar os Ouvidores que ingressam na rede e a monitoração de sua atuação na Ouvidoria setorial.

Referindo-se à divulgação e canais de atendimento, o titular da Coordenadoria de Fomento ao Controle Social (Cfocs), da Controladoria e Ouvidoria-Geral do Estado (CGE), afirmou que a divulgação do instituto de Ouvidoria e de seus canais de atendimento depende da parceria com a Casa Civil do governo do estado (principalmente a confecção de material como cartazes e fôlderes) e está limitada à Assessoria de Comunicação da CGE por intermédio de redes sociais, matérias em sites e jornais e palestras realizadas por Ouvidores voluntários com alunos de escolas públicas de ensino médio da capital e do interior, no âmbito do programa de educação social da Seduc. 0 governo alega poucos recursos financeiros para o projeto. Quase todos os respondentes, dentre Ouvidores e integrantes do órgão central de Ouvidoria, admitiram que a divulgação da Ouvidoria para a sociedade não é eficaz. A divulgação teria maior efeito se as Ouvidorias setoriais atuassem mais com suas áreas de comunicação e se a Casa Civil reconhecesse a Ouvidoria como política de governo e não como um setor específico da CGE.

Os canais de atendimento do Sistema de Ouvidoria do Estado são compostos por: a) central de atendimento telefônico, que realiza atendimento gratuitamente pelo ramal 155 e por retornos relacionados à Ouvidoria e acesso à informação - criada em janeiro de 2008 e situada na cidade de Canindé, constitui-se em um dos principais canais receptores e porta de entrada das demandas de Ouvidoria de todo o estado, ela vem permitindo a universalização dos serviços prestados pela Ouvidoria do estado do Ceará; b) e-mail - ouvidoria.geral@cge.ce.gov.br; c) acesso pela internet; d) atendimento presencial e por correspondência, de modo a viabilizar a recepção e o registro de manifestações como: sugestões, elogios, reclamações, críticas, denúncias, solicitações de serviços e informações pertinentes ao poder executivo estadual; e) redes sociais, compostas pelo microblog Twitter (@OuvidoriaCeara) e Facebook (/OuvidoriaCeara); e f) o Reclame Aqui da Ouvidoria-Geral do Ceará. As demandas dos cidadãos que forem recebidas por Twitter ou Facebook são cadastradas por técnicos da Célula de Ouvidoria da CGE no sistema automatizado (SOU) e encaminhadas para os órgãos e entidades do governo responsáveis pelo assunto. $O$ atendimento presencial pode ser buscado na sede da CGE ou em qualquer órgão ou entidade do Poder Executivo estadual.

Com relação à estrutura e posição hierárquica da Ouvidoria, ela é organizada sob a forma de célula e fortalecida pelo fato de se encontrar na Governadoria, como assessoria direta do Governador. É parte integrante da CGE, sendo subordinada à Cfocs, com as células de Transparência e Ética, de Acesso à Informação e com a central de atendimento 155. A Ouvidoria faz, portanto, parte das atividades de controle da Administração Pública, de acordo com a Emenda Constitucional $n^{\circ}$ 75, de 20 de dezembro de 2012 (CEARÁ, 2012b). 
Esse posicionamento da Ouvidoria na estrutura organizacional do órgão/entidade atende ao que é recomendado no plano federal, pois "o posicionamento adequado e satisfatório da Ouvidoria, dentro da estrutura organizacional do órgão/entidade, é como unidade de assistência direta e imediata ao titular do órgão/entidade, ou estrutura de nível equivalente" (BRASIL, 2013, p. 25).

As atividades do Sistema de Ouvidoria do estado são realizadas pelo órgão central de Ouvidoria por meio das equipes de monitoramento e qualidade da Célula de Ouvidoria da CGE, pela rede de Ouvidorias e pela central de atendimento telefônico 155. A equipe de monitoramento é responsável por supervisionar prazos de respostas das manifestações e pelo redirecionamento de manifestações/denúncias para Ouvidorias setoriais. A equipe de qualidade é responsável pela análise e validação das respostas dos Ouvidores aos usuários/cidadãos.

Diante dessas informações, observa-se que a Ouvidoria do estado do Ceará atende também à orientação de que deve se integrar sistemicamente a outros órgãos da Administração Pública. De fato, segundo a Controladoria-Geral da União (BRASIL, 2012b, p. 8), para o efetivo funcionamento das Ouvidorias, elas precisam se relacionar de forma continuada e em rede, presencial ou virtualmente, com outros órgãos e cidadãos, "visando compartilhar conhecimentos, aprender e gerar inovações no trabalho das Ouvidorias".

Observou-se que algumas Ouvidorias do estado atuam com estrutura aquém da necessária. Essa deficiência influencia no cumprimento do prazo das respostas de manifestações ao usuário/ cidadão, além de inviabilizar atendimentos presenciais.

A aceitabilidade da Ouvidoria por parte dos dirigentes dos órgãos/entidades setoriais tem evoluído, para o que tem contribuído a posição ocupada pela Ouvidoria-Geral no organograma da governadoria, assessorando diretamente o governador, e a atuação sistemática do órgão central no monitoramento das atividades. Com isso, a Ouvidoria-Geral se mostra com maior força, além de atuar como órgão de atividade de controle da Administração Pública no estado do Ceará.

Quanto ao fluxo do processo de atendimento às manifestações de Ouvidoria, seguindo as diretrizes contidas no Decreto 30.938/2012 (CEARÁ, 2012a), ele se inicia quando o cidadão (usuário) envia a manifestação pelos canais disponibilizados pela Ouvidoria do estado. Ao registrar manifestação na internet pelo sistema automatizado (SOU), o usuário recebe um e-mail automático com protocolo e senha para acompanhamento da demanda. Se a manifestação for por telefone, a central atende, registra e classifica a demanda no SOU. Se for enviada por e-mail ao órgão setorial ou feita pessoalmente (presencial), o Ouvidor da setorial registra e classifica a manifestação no sistema. 0 sistema encontra-se adaptado para receber manifestações anônimas.

De acordo com o Decreto 30.474/2011 (CEARÁ, 2011), o prazo para resposta das manifestações de Ouvidoria é de até 15 dias, podendo ser prorrogado por igual período com a anuência do gestor do órgão setorial. A partir do momento em que o sistema gera protocolo e senha, a contagem do prazo se inicia, considerando data e horário. Após o registro da manifestação, ela é encaminhada diretamente à Ouvidoria do órgão referente à solicitação, exceto as denúncias, que passam por uma pré-análise da equipe de monitoramento da Célula de Ouvidoria da CGE para depois serem encaminhadas ao destino, obedecendo os casos definidos na Portaria 107/2014 (CEARÁ, 2014). O SOU permite que um órgão compartilhe a mesma demanda com outro, fazendo com que o último contribua também com a resposta. O sistema permite transferir manifestações para os gestores 
das áreas do órgão/entidade responderem; a resposta então é repassada ao Ouvidor para melhoramento e, em seguida, encaminhada à CGE. A mesma resposta passa por uma análise e validação da Controladoria e, depois de validada, é encaminhada ao cidadão. Caso as respostas não estejam claras ou não atendam às orientações da CGE, são devolvidas às Ouvidorias setoriais para que realizem as alterações necessárias. Nos casos de descumprimento do prazo de resposta, a CGE articula sua prorrogação com a gestão superior dos órgãos e entidades, com vistas a garantir o atendimento no prazo estabelecido.

Os prazos das manifestações e a qualidade das respostas fornecidas pelas Ouvidorias setoriais são acompanhados pela equipe de monitoramento da Célula de Ouvidoria da CGE. Esses critérios são chamados de resolubilidade das manifestações, compreendendo as manifestações respondidas ao usuário no prazo estabelecido e com conteúdo da resposta válido. O conteúdo passa por validação da equipe de qualidade da Ouvidoria antes de ser encaminhado ao usuário-cidadão; a equipe se comunica com os Ouvidores da rede de Ouvidoria para esclarecimentos relacionados às manifestações. As manifestações (principalmente as denúncias) muitas vezes são encaminhadas para apreciação da área de Auditoria e de controle interno preventivo da CGE para adoção de providências.

O processo de atendimento das manifestações serve aos propósitos da Ouvidoria. Adotando um modelo de gestão em rede, o sistema atual do Ceará caminha à frente de modelos existentes em outros estados do país, uma vez que garante a uniformidade de processos e procedimentos e a vinculação das setoriais à direção superior de seus respectivos órgãos. O Sistema de Ouvidoria utiliza ferramenta automatizada com o fluxo do processo de atendimento, permitindo o monitoramento pelo órgão central de Ouvidoria da CGE, e atende aos princípios de celeridade e padronização.

Com relação ao tratamento e destino da informação gerada a partir das manifestações, as Ouvidorias setoriais fornecem relatórios semestrais desde o ano de 2011, com dados e estatísticas produzidos a partir das manifestações, atendendo às diretrizes contidas nos Decretos 30.474/2011 (CEARÁ, 2011) e 30.938/2012 (CEARÁ, 2012a). Esses dados são consolidados pelo órgão central de Ouvidoria da CGE em relatórios anuais de gestão de Ouvidoria, com informações sobre demandas por meios de entrada, quantidade de manifestações por grupo e tipo, manifestações classificadas de acordo com os eixos e temas dos programas de governo, quantidade de manifestações por macrorregiões, tempo médio de resposta, órgãos mais demandados, satisfação do usuário e ações inovadoras feitas pelas setoriais com informações sobre a participação do Ouvidor na gestão (em decisões e no planejamento, em comitês executivos etc.). Também são apresentadas recomendações dos Ouvidores e da CGE aos órgãos/entidades setoriais, com solicitação de resposta das iniciativas implementadas. Os resultados dessas ações são informados no relatório do semestre seguinte. Os relatórios semestrais e de gestão consolidados são disponibilizados no site da CGE.

A intenção da CGE é dar às recomendações da Ouvidoria o mesmo tratamento conferido às da Auditoria. Para que isso se concretize, a CGE está aprimorando a ferramenta denominada Plano de Ação para Sanar Fragilidades (Pasf). Esse sistema será alimentado pelo órgão/entidade setorial e permitirá a integração com a base de dados das informações de Ouvidoria. Infelizmente, os dados dos relatórios, hoje, não são adequadamente utilizados porque falta integração com o órgão de planejamento e com a governadoria do estado no intuito de subsidiar o planejamento das políticas públicas e o orçamento. 


\subsection{Evidências do Uso da Informação da Ouvidoria como Contribuição para a Gestão Pública do Estado}

São realizadas ações pelos órgãos setoriais em resposta às recomendações e denúncias recebidas do cidadão, oriundas dos Relatórios Gerenciais de Ouvidoria. A seguir são relatadas ações que provocaram mudanças significantes para o serviço público do estado motivadas pela Ouvidoria.

A exemplo, foi sugerido à Secretaria da Saúde (Sesa) melhorar a articulação entre a gestão de pessoas e o processo de agendamento e a realização de procedimentos nas unidades assistenciais da Sesa, além de apresentar as necessidades de melhorias na dinâmica interna de trabalho, com a reestruturação dos fluxos de informações, normas e rotinas, para garantir maior agilidade e eficiência nos serviços. Ações implementadas pela Ouvidoria da Sesa nesse sentido foram a construção de unidades de saúde e, na área da gestão, o encaminhamento das demandas relacionadas a estrutura e funcionamento às áreas administrativas das unidades, para aprimoramento e melhoria das instalações.

À Secretaria da Fazenda do Estado (Sefaz), foi sugerido implementar o sistema de cupom eletrônico para dinamizar o processamento dos documentos fiscais da Campanha Sua Nota Vale Dinheiro, bem como agilizar o pagamento dos créditos dos participantes. Para isso, foi efetivada a implantação do Sistema de Cupom Eletrônico (DANFE), no ano de 2015, contribuindo para a diminuição na quantidade de manifestações relacionadas ao Programa Sua Nota Vale Dinheiro. Outra área de grande incidência de reclamações foi a de Consultoria Tributária. As informações da Ouvidoria possibilitaram algumas transformações, como inclusão de pessoas com melhor perfil e mudanças de gestão e procedimentos, reduzindo o índice de reclamações.

As providências tomadas pela Ouvidoria da Secretaria de Segurança Pública e Defesa Social (SSPDS) foram relacionadas ao aumento do policiamento ostensivo/preventivo; reforço nas ações integradas na área de segurança pública no Ceará, com o cumprimento das metas estabelecidas; aumento de abordagens e autuações pelo Batalhão de Policiamento do Meio Ambiente nas ocorrências de poluição sonora; melhoria nos atendimentos da Ciops (tecnológica, pessoal, capacitação, política de segurança), bem como redução na fila de espera, o que impactou na redução do tempo de atendimento das ocorrências; implementações e melhorias nos sistemas tecnológicos de monitoramento e ações de segurança pública; continuidade das ações do Programa em Defesa da Vida em todo o Estado do Ceará por meio de Áreas Integradas de Segurança (AISs); continuidade nas ações de meritocracia para o alcance da meta de redução de crimes; intensificação em ações estratégicas nas grandes operações; o Pacto por um Ceará Pacífico apresenta novas diretrizes no combate às drogas e prevenção à violência com a redução no índice de crimes violentos, e o programa "Crack, é possível vencer" registra queda de $27 \%$ em mortes violentas nas comunidades atendidas.

Na Polícia Militar (PMCE), a Ouvidora citou: soluções sobre pensão alimentícia; esclarecimentos ao cidadão sobre como proceder em relação à poluição sonora, objeto de grande quantidade de reclamações.

Na Companhia de Água e Esgoto do Ceará (Cagece), foi implantado o fluxo de apuração de denúncias como melhoria para dar mais transparência ao cidadão. Outra ação para fluir o fluxo de respostas entre as áreas da companhia foi a implantação de facilitadores em cada unidade de ne- 
gócio. É enviado a cada bimestre Relatório de Gestão de Ouvidoria aos gestores por e-mail, com os assuntos mais demandados e estatísticas de tempo de respostas e quantidade de demandas por unidade, no intuito de auxiliar nas atividades internas dos gestores.

No Departamento Estadual de Trânsito (Detran-CE), o Ouvidor relata sobre a grande quantidade de denúncias concentrada na área de Exames, relacionadas à postura do avaliador na avaliação do candidato no exame prático de direção. A ação da Ouvidoria resultou na implantação do serviço de monitoramento, feito por empresa licitada, que consiste na adaptação do veículo com áudio e vídeo e monitoramento por profissionais durante a realização do exame, respaldando tanto o candidato quanto o avaliador. Essa ação já se encontra em fase de experiência. Relata casos de demandas reincidentes no interior, cujo atendimento da recomendação resultou na demissão de funcionários.

Na Polícia Civil, o Ouvidor relata que, em virtude de ação da Ouvidoria, as soluções muitas vezes ocorrem em articulação direta do Ouvidor com os colaboradores e gestores das áreas implicadas, sem ações planejadas, graças ao alto dinamismo da instituição. Exemplo de êxito foi uma melhoria no sistema S25, o qual permite o registro instantâneo de boletim de ocorrência de roubo de veículo feito nos finais de semana nas delegacias de polícia. Antes, a informação do veículo roubado só era registrada na segunda-feira subsequente, tornando o processo moroso. Outra ação da Ouvidoria foi a instalação de totens na instituição para registro de Boletins de Ocorrência, dando agilidade ao processo. Outra ação foi referente à realocação de delegados nas delegacias, em virtude de reclamações dos cidadãos.

No Instituto de Saúde dos Servidores do Estado do Ceará (Issec), a Ouvidora relata situação crítica de problemas relacionados à liberação de exames e que foi resolvida com a articulação das informações da Ouvidoria com a empresa autorizadora de exames; outra ação foi a implantação do sistema SISWEB pela área de Auditoria da instituição, através de Cartão Magnético de Saúde do Issec, com a intenção de que pacientes do interior tenham prioridade no atendimento.

A Ouvidora da Secretaria da Educação do Estado (Seduc) mencionou o caso do Setor de Documentação Escolar - que trata de documentação de escolas extintas -, alvo de muitas reclamações por se encontrar sempre fechado no horário estabelecido para atendimento. Pela articulação da Ouvidoria, foi criado um link na página da Seduc para solicitação de documento a fim de que o usuário venha ao Setor apenas para o recebimento. Além disso, aproveitando uma reforma da estrutura física da Seduc, por provocação da Ouvidoria, o setor foi alocado próximo à sala da Ouvidoria e com local adequado para atendimento. Ainda sim, foi restabelecido o horário para o atendimento e o responsável pelo mau procedimento foi afastado da unidade.

\section{CONSIDERAÇÕES FINAIS}

O resultado da investigação revela que, como parte do Sistema de Ouvidoria, foram implantados um órgão central de Ouvidoria - com atribuições associadas ao controle público - e unidades setoriais descentralizadas. O órgão central está vinculado à governadoria, o que atribui à Ouvidoria uma posição organizacional de prestígio e poder para o exercício de suas funções, em linha com a legislação e com as recomendações dos modelos teóricos de Ouvidoria presentes na literatura da 
área. A despeito dessas condições relativamente favoráveis, foi possível identificar que a estrutura implantada ainda não consegue realizar todo o seu potencial de contribuição nos papéis de intermediar a relação governo-cidadão e, particularmente, contribuir para a melhoria da gestão e da prestação de serviços públicos.

Algumas deficiências foram relacionadas, dentre elas estão as diferenças de aceitação e de compreensão do papel da Ouvidoria por gestores e técnicos; a falta de utilização das informações dos relatórios da Ouvidoria para a introdução de melhorias sistêmicas e de processos, em lugar de apenas resolver ou dar uma explicação para situações específicas de insatisfação do cidadão; e a falta de financiamento para projetos relevantes da área, em particular para melhoria de processos, educação permanente dos profissionais, divulgação das iniciativas e difusão da filosofia e do papel da Ouvidoria em uma democracia.

A participação na mostra pesquisada de Ouvidores recém-ingressados na Rede de Ouvidoria comprometeu um pouco a qualidade dos dados coletados. A carência foi suprida com a participação de auxiliares mais experientes no momento da entrevista.

Tendo em conta essas considerações e para o aperfeiçoamento do sistema e melhoria de sua eficácia, são feitas as recomendações mais urgentes como: realizar a avaliação sistemática e o replanejamento das iniciativas de qualificação dos Ouvidores e gestores; redefinir o monitoramento e a avaliação da atuação da Ouvidoria e dos Ouvidores, com introdução de indicadores de desempenho; realizar, pelo órgão central de Ouvidoria, ações mais proativas nos órgãos setoriais e na governadoria para aproveitamento mais adequado das informações dos relatórios da área; promover regularmente pesquisa com os cidadãos para identificar a satisfação com os serviços da Ouvidoria e identificar sugestões de melhoria; realizar diagnóstico e adotar medidas para a melhoria das condições de funcionamento da rede de Ouvidores em Fortaleza e, em particular, no interior do estado; e promover maior aproximação entre o órgão central de Ouvidoria e os órgãos estratégicos de planejamento e gestão do governo, de forma a viabilizar maior participação da área nas iniciativas de planejamento e gestão. As mudanças internas nas instituições, descritas neste documento e provocadas pela atuação da Ouvidoria setorial, mostram a missão desse instituto como promissor parceiro na gestão.

Os autores esperam que o resultado desta pesquisa possa contribuir para a melhoria de atuação da Ouvidoria no governo do estado do Ceará. Espera-se ainda que os resultados do trabalho demonstrem a importância da Ouvidoria para a gestão pública e contribuam para incentivar outras pesquisas investigatórias sobre sua atuação e as contribuições dessa instituição para o exercício da cidadania e a melhoria da gestão pública.

\section{REFERÊNCIAS}

BRASIL. Constituição (1988). Diário Oficial da União, Brasília, DF, 5 out. 1988. Disponível em: <https://bit.ly/1blJ9XW>. Acesso em: 13 abr. 2018.

. OUVIDORIA-GERAL DA UNIÃO. Orientações para implantação de uma unidade de Ouvidoria: rumo ao sistema participativo. 5. ed. rev. e atual. Brasília, DF: Controladoria-Geral da União, 2012a (Coleção OGU). 
CONTROLADORIA-GERAL DA UNIÃO. Controle social: orientações aos cidadãos para participação na gestão pública e exercício do controle social. Brasília, DF: Secretaria de Prevenção da Corrupção e Informações Estratégicas, 2012b (Coleção Olho Vivo). Disponível em: <https://bit.ly/1GP02Di>. Acesso em: 1 ago. 2015.

MINISTÉRIO DO PLANEJAMENTO, ORÇAMENTO E GESTÃO. Guia de orientação para a gestão de Ouvidorias. Brasília, DF, 2013.

CEARÁ. Lei Ordinária Estadual $n^{\circ} 13.875$, de 7 de fevereiro de 2007. Dispõe sobre o modelo de gestão do poder executivo, altera a estrutura da administração estadual, promove a extinção e criação de cargos de direção e assessoramento superior, e dá outras providências. Diário Oficial do Estado do Ceará, Fortaleza, 7 fev. 2007. Série 2, ano 10. n. 27, p. $1-7$.

Decreto Estadual $n^{\circ} 30.474$, de 29 de março de 2011. Institui o sistema de Ouvidoria - SOU, e dá outras providências. Diário Oficial do Estado do Ceará, Fortaleza, 30 mar. 2011. Série 3, ano III, nº 61, p. 1.

Decreto Estadual $n^{\circ} 30.938$, de 10 de julho de 2012. Regulamenta o Sistema de Ouvidoria do Poder Executivo Estadual, e dá outras providências. Diário Oficial do Estado do Ceará, Fortaleza, 12 jul. 2012a. Série 3, ano IV, n. 132, caderno único, p. 1.

Emenda Constitucional $n^{\circ} 75$, de 20 de dezembro de 2012. Altera dispositivos da Constituição Estadual. Diário Oficial do Estado do Ceará, Fortaleza, 27 dez. 2012b. Série 3, ano IV, n. 244, p. 214.

Portaria $\mathrm{n}^{\circ}$ 107, de 13 de agosto de 2014. Dispõe sobre a instituição da Comissão Permanente de Apuração de Denúncias recebidas pela Controladoria e Ouvidoria-Geral do Estado e dá outras providências. Diário Oficial do Estado do Ceará, Fortaleza, 21 ago. 2014. Série 3, ano VI, n. 154, p. 6.

GIL, A. C. Como elaborar projetos de pesquisa. 4. ed. São Paulo: Atlas, 2002.

GOIS, A. L.; LACERDA, L. F. F.; SOUZA, S. G. A atuação proativa de Ouvidoria em um hospital público. In: PEREZ, J. R. R.; BARREIRO, A. E. A.; PASSONE, E. (Org.). Construindo a Ouvidoria no Brasil: avanços e perspectivas. Campinas: Ed. Unicamp, 2011. p. 187-197.

MORAES, D. C. P. et al. Ouvidorias como dispositivos de gestão participativa de políticas públicas: sua história e experiência no Pará. In: CONGRESSO CONSAD DE GESTÃO PÚBLICA, 3, Brasília, DF, 2010. Anais... Brasília, DF Consad, 2010.

NASSIF, G. C. As Ouvidorias Públicas no contexto de um novo modelo de governança. Revista do Tribunal de Contas do Estado de Minas Gerais, Belo Horizonte, v. 73, n. 4, p. 45-60, out.-dez. 2009.

OLIVEIRA, J. E. Ouvidoria pública brasileira: evolução de um modelo único. In: VISMONA, E. (Org.). A Ouvidoria brasileira. São Paulo: Associação Brasileira de Ouvidores; Imprensa Oficial do Estado de São Paulo, 2005. p. 45-54.

PINTO, E. A Ouvidoria como instrumento de controle social. Revista TCMRJ, Rio de Janeiro, ano XXVIII, n. 46, p. 31-36, jan. 2011. Disponível em: <https://bit.ly/2GQgRn6>. Acesso em: 11 abr. 2018.

SOUZA, R. C. R. A Ouvidoria como instrumento de avaliação e melhoria da qualidade dos cuidados de enfermagem. 2010. 102 f. Dissertação (Mestrado em Enfermagem) - Escola de Enfermagem Alfredo Pinto, Universidade Federal do Estado do Rio de Janeiro, Rio de Janeiro, 2010.

VERGARA, S. C. Métodos de pesquisa em administração. São Paulo: Atlas, 2005.

VIEIRA, E. D.; LIMA, H. M. F. Cidadania e controle social: a Ouvidoria como instrumento de controle e participação na Administração Pública. Revista do Mestrado Profissional em Planejamento em Políticas Públicas, Fortaleza, p. 616-638. Conhecer, debate entre o público e o privado, Fortaleza, v. 1, n. 2, mai/ago. 2011.

VISMONA, E. L. A evolução das Ouvidorias no Brasil. In: PEREZ, J. R. R.; BARREIRO, A. E. A.; PASSONE, E. (Org.). Construindo a Ouvidoria no Brasil: avanços e perspectivas. Campinas: Unicamp; Ouvidoria, 2011. p. 29-42. 